\title{
ТЕОРЕТИКО-МЕТОДОЛОГИЧЕСКИЕ ОСНОВЫ ИССЛЕДОВАНИЯ ИНФОРМАЦИОННЫХ ВОЙН И ПСИХОЛОГИЧЕСКИХ ОПЕРАЦИЙ
}

\begin{abstract}
Аннотация. Возникла необходимость для создания новых методов ведения борьбы на международной арене, что в итоге привело к появлению теории информационных войн. Дополнительный импульс развитию методов информационно-психологического противостояния добавило то, что после Второй Мировой войны и возникшей потсдамско-вашингтонской системь, мир оказался разделенньм на два больших лагеря, противостояние между которыми проходило и в идеологической сфере. Совокупность вышеперечисленных факторов, а также бурное развитие СМИ и новых средств коммуникации привело к появлению нового пространства международной политики - киберпространства, что отмечается во многих работах западных авторов. Методологическую основу исследования составляют системный, структурно-функциональный, сравнительно-исторический, сравнительно-политический, геополитический и культурно-иивилизаиионный подходы, методы анализа, синтеза, индукиии, дедукиии, моделирования, наблюдения. Целью данной работы является изучения явления информационно-психологического воздействия как нового явления в политической сфере жизни человечества. Задачами данной работы является описание истории развития информационных и кибервойн, изучение методов и технологий а также изучение опыта зарубежных стран. К томуже важной задачей является выявление отличий информационных войн от классических политических кампаний разной направленности и анализ явления инбормационных и кибервойн с точки зрения теории политики и теории международных отночений.
\end{abstract}

Ключевые слова: политика, управление, международные отношения, информационная война, психологическая операция, психологическая война, информационное оружие, политическая коммуникация, конфликт, информаицонная безопасность

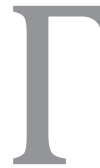

оворя об актуальности исследования информационных войн (ИВ), следует отметить проблемы исследования ИВ как явления и инструмента политического воздействия. Данные проблемы связаны, прежде всего, не с недостаточным вниманием к данной теме (оно, скорее, избыточно, а сам термин слишком популярен в политическом и околополитическом дискурсе), а с недостаточностью некого эмпирического и теоретического бэкграунда для исследования данного явления и некой ограниченностью подходов к изучению информационных войн только как политического или как военного явления, в то время как данный феномен, а соответственно и его исследование лежит, в области междисплинарных изысканий с привлечением знаний многих политических наук - политической психологии, менеджмента, коммуникативистики, государственной политики, международных отношений а так же военной стратегии и тактики.

Основной гипотезой данного исследования является следующее положение: информаци- онная война представляет собой совокупность информационных, политических и кибернетических операций, проводимых в информационном и киберпространстве с широчайшим применением политических, военных и психологических технологий, причем информационная война как метод и инструмент является уникальным явлением.

1. Информационные операции как основная организационная форма информационной войны

В современной российской политической науке отсутствует общепринятое определение информационных войн, что вызывает некоторые трудности в исследовании данного явления. Определений одной информационной войны существует несколько десятков, причем зачастую они довольно сильно отличаются друг от друга. Если брать за основу разбор термина «информационная война» в русском языке, то можно вывести довольно широкую трактовку: информационная война - ограниченный по времени конфликт 
между государствами, ведущийся с помощью информационного оружия. Существует и второй подход - рассмотреть данный термин в английском языке (information warfare), калькой с которого является термин «информационная война» в русском языке. При переводе с английского возникает два значения information warfare: информационная война и информационное противоборство.

Однако, стоит отметить, что сам по себе термин вышел из военной среды - впервые данный термин был использован в докладе для компании Boeing за авторством Томаса Роны (Thomas Rona). Однако, для нас сейчас не является приоритетом рассмотрение эволюции термина «Информационная война» (сама по себе тема эволюции термина «информационная война» весьма интересна, но, к сожалению, объем данной работы не позволяет ее полноценно раскрыть).

Начиная с 90-ых годов XX века, термин «информационная война», «информационные операции» входит в армейские документы МО США, ведущих стран НАТО (Великобритания, Франция, ФРГ) и НОАК. На сегодняшний день, термин «информационные операции» определяется военными кругами США как действия, предпринимаемые с целью оказания влияния на принятие решений в поддержку собственных политических и военных целей путем воздействия на информацию, информационные процессы и системы управления противника, при одновременной защите собственной информации и информационных систем. При этом в двухтысячных годах происходило постепенно укрупнение термина «информационные операции» и на сегодняшний день информационные операции организационно состоят из нескольких видов специальных операций, а именно: психологические операции (Psychological Operations), Military Deception, Operational Security, Computer Network Operations и Electronic Warfare, причем последние два типа представляют собой части киберопераций (Cyberwarfare). Однако, отдельно оговаривается следующий терминологический вопрос - с конца 90-ых годов армейское руководство США признало, что термин «информационная война» является устаревшим и поэтому необходимо заменить его термином «информационная операция». Поэтому в данной работе термины «информационная операция» и «информационная война»не являются взаимозаменяемыми, да и само использование термина «информационная война» не является корректным в связи с тем, что информационные операции зачастую проводятся без объявления войны и логичнее данный термин заменить на «информационное воздействие».

\section{2. Психологические операции как основная организационная форма ИВ.}

К сожалению, в области детерминации психологических операций на сегодняшний день в отечественной политической науке ситуация схожая с общей проблемой исследования информационных операций. К тому же, и без того депрессивную ситуацию с изучением данного явления усиливают различные авторы, которые не стремясь качественно изучать обозначенный феномен, выстраивают свои предположения на популярных конспирологических теориях без должного применения научной методологии.

Чтобы разобраться в поставленном вопросе, для начала необходимо определиться с теми терминами, которые необходимы для разбора данной темы, а именно: пропаганда, психологическая операция и психологическая война.

Термин «пропаганда» среди всех перечисленных, является наиболее старым. Его происхождение восходит к христианской католической церкви, а именно к учрежденной папой Григорием XV организации Congregatio de Propaganda Fide, что в переводе означает «Конгрегация распространения веры». Однако в дальнейшем происходит перенос названия организации на целое явление, которое наиболее активно развивается в XIX и XX веке. Один из классиков теории пропаганды Э. Бернейс в своей книге «Пропаганда» определяет ее следующим образом: пропаганда есть механизм широкомасштабного внушения взглядов ${ }^{1}$. В последующем, происходит сужение данного термина и его отделение от термина «психологическая война» другим не менее известным практиком и теоретиком пропаганды и психологической войны Полем Лайбарджером. В своей книге «Психологическая война» он определяет пропаганду следующим образом: «Пропаганда состоит в планомерном использовании любого средства общения для

\footnotetext{
${ }^{1}$ Бернейс Э. М.: Пропаганда.- M., Hippo Publishing LTD, 2010
} 


\section{Тренды и управление 3(7) • 2014}

воздействия с определенной целью на ум, чувства и поведение данной группы людей». ${ }^{2}$

В то же время психологическая война трактуется им как продолжительный по времени комплекс мероприятий психологического (в том числе и пропаганды), информационного, экономического, политического и военного характера для достижения поставленных целей путем изменения мнений, ценностей, настроений и установок среди войск и населения противника.

Таким образом, пропаганда, согласно П. Лайбарджеру, является лишь инструментом ведения психологической войны, что подтверждается автором на примере исследования нескольких кейсов - начиная от древнейших времен и заканчивая войной в Корее. При этом он весьма четко ставит проблему разграничения собственно психологической войны и ведения войны психологическими инструментами. То есть в первом случае декларируется проведение некого комплекса мероприятий для морально-психологического воздействия на противника и в мирное время в том числе; во втором же случае оговаривается, что в случае обычной, конвенциональной войны, необходимо помнить про психологическое состояние собственного населения и войск и вести войну за умы противника.

Однако, исследование Лайбарджера носило скорее ретроспективный характер относительно психологической войны и ее элементов и повествует о ведении войны психологическими инструментами с анализом пропаганды, рекламных технологий, пиара и в дальнейшем развитии гуманитарных наук. Реклама, пиар и пропаганда стали пусть и родственными, но разными предметами.

Следующим шагом в развитии военно-политической мысли в данном направлении становится выделение понятия «психологическая операция», которое закрепляется уже в официальных военных документах США, прежде всего в Доктрине психологических операций ВС США JP 3-53, которая переиздавалась и дополнялась на протяжении нескольких лет.

Согласно наставлению ВС США (Joint Publication 3-53 Doctrine for Joint Psychological Operations), психологическая операция (Рsy0p) - это плановые мероприятия по передаче отобранной информации и индикаторов (selected information and indicators)

2 Лайнбарджер. П. Психологическая война.- М.: 1962 зарубежной аудитории с целью повлиять на их эмоции, мотивы, логические объяснения и в конечном счете на нужное поведение иностранных правительств, организаций, групп и отдельных людей.

Также подчеркивается, что психологические операции являются важной частью военной, политической, экономической деятельности США и их целью в военное и мирное время является информирование и влияние на публику. Именно то, что психологические операции проводятся в мирное время и отличает их от психологической войны. Но, так как термин появился из военной среды, необходимо отметить деление психологических операций на три уровня - стратегический, оперативный и тактический.

Стратегические психологические операции осуществляются в интересах достижения долгосрочных целей, призванных создать благоприятную психологическую обстановку для ведения военных действий и проведения внешней и внутренней политики. Такие операции обычно носят глобальный характер.

Оперативные психологические операции осуществляются в интересах достижения среднесрочных целей, в поддержку военных кампаний и проводимой региональной политики. Объектом таких операций обычно является население определенного региона. Также отмечается, что данные операции проводятся непосредственно перед началом войны или крупномасштабной операции (например, операции «Щит пустыни» непосредственно на театре боевых действий).

Тактические психологические операции осуществляются в интересах достижения краткосрочных целей, в поддержку командиров тактического звена. Объектом таких операций обычно является противостоящая группировка войск противника.

Стратегический уровень наиболее интересен, так как на данном уровне психологические операции призваны создать благоприятную психологическую обстановку для ведения военных действий.

Стоит отметить, что помимо военных психологических операций, существуют и психологические операции, проводимые Госдепартаментом и ЦРУ. Ключевых отличий между операциями, проводимыми разными ведомствами нет, т.к. на- 
лажена отличная координация между данными структурами.

Психологические операции на сегодня включают практически весь арсенал, которым располагала пропаганда. Так, к арсеналу психологических операций относятся весьма традиционные инструменты:

1) Распространение различных агитационных материалов через армейские органы психологической борьбы (организация теле- и радиовещания, создание и распространение печатных агитационных материалов, создание и размещение агитационных материалов в сети Интернет).

2) Распространение различных агитационных материалов через СМИ различными путями - как трансляция агитационных материалов, так и работа с журналистами - организация брифингов, создание пресс-релизов и т.д. Стоит отметить, что данный инструмент получил свое отдельное название - Civil Affairs operation.

3) Распространение различных агитационных материалов через Интернет

4) Распространение слухов

Стоит отметить, что зачастую размещение агитационных материалов через СМИ или через Интернет происходит благодаря налаженной работе с журналистами и блоггерами. В частности, сюда можно отнести практику так называемых «вживленных журналистов» ${ }^{3}$.

Помимо этого, существуют и другие инструменты психологических операций, а именно:

1) «Операции под чужим флагом» - фальсификация материалов и последующее их тиражирование и/или распространение через СМИ и Интернет для создания инфоповода или оправдания для начала действий. В качестве примера можно привести инцидент в Глейвице или же недавний медиапример - история с миссией «Ни слова по-русски» в игре Call of Duty: Modern Warfare 2.

2) Дискредитация текущего правительства и его программ путем распространения компромата, подложных данных, создания правительства в изгнании или оппозиционных сил.

3) Развешивание ярлыков. Весьма показательными являются два схожих кейса гражданской войны в Сирии и текущей ситуации на Украине. Так, в Сирии правительство Башара

\footnotetext{
${ }^{3}$ Газетов В. «Когда журналист сильнее солдата» - М., Независимое военное обозрение 04.04.2014
}

Асада рисуется абсолютным злом, в то время как боевики (несмотря на большое количество участников из Аль-Каиды и других радикальных исламистких организаций) - борцами за свободу. В случае же ситуации на Юго-Востоке Украины (в непризнаных Донецкой и Луганской народной республиках) - правительство Украины изображается «хорошей» стороной, в то время как сепаратисты - абсолютным злом. Причем интересна реакция международного сообщества на выборы в Сирии и на выборы на Украине. В одинаковых исходных условиях (гражданская война, наличие мятежных регионов и провинций где не проходят выборы) - Президент Украины Порошенко П.А. признается легитимным со стороны международного сообщества, в то время как переизбранный Б. Асад - нелегитимным.

\section{3. Методология исследования ИВ и ПсО}

Одним из краеугольных камней исследования ИВ и ПсО как инструмента являются методы и наработки политической психологии, социологии, политической коммуникативистики и технологий пропаганды, которые наиболее глубоко и широко были разработаны в XX веке. Стоит также отметить и необходимость использования в проведении ПсО и ИО теории политической коммуникации для разработки стратегического замысла кампании и последующего тактического выбора средств. Однако же, в рамках исследования ИВ и ПсО как явления мировой политики и международных отношений следует отметить наработки сторонников реализма и в отдельности исследования Дж. Ная в области мягкой и жесткой силы и стратегии комбинированного использования данных сил, которая представляется Дж. Наю как концепция «умной силы». Такой подход самим автором называется либерально-реалистким, что с учетом предложенной автором новой парадигмы международных отношений (согласно данной схеме, на современном этапе на международной арене связи устанавливаются не только между государствами или между государством и надгосударственным актором, но и между негосударственными акторами, нгосударственными акторами и государствами, негосударственными акторами и надгосударственными структурами). 


\section{Тренды и управление 3(7) • 2014}

Однако же, для наиболее полного освещения методологии исследования ИВ и ПсО необходимо рассмотреть все методы по группам.

Методы политической психологии, социологии и политической коммуникативистики, используемые в исследовании ПсО и ИВ необходимы для анализа информационных и психологических операций как отдельного события с целью разбора тех инструментов, которые применяются для их проведения - методы манипулирования, массового поведения, каким образом выстроена коммуникация в процессе реализации плана психологической и информационной операции. В рамках данного пункта наиболее интересны концепции, разработанные Уолтером Липпманом и Жаком Эллюлем.

В целом, модель, предложенная Липпманом и в дальнейшем доработанная Эллюлем, строится на следующих постулатах - общественное мнение строится на стереотипах, которые обладают рядом весьма важных для проведения информационных и психологических операций свойств, а именно - стереотипы весьма просты и поэтому легки для запоминания, стереотипы весьма быстро распро- страняются в обществе и перенимаются отдельным индивидом от коллектива и стереотипы весьма живучи.

По сути дела, появление данных работ в начале XX века предопределило дальнейшее развитие пропаганды на протяжении века. Еще более дополнило данные работы изучение практического опыта нацисткой пропагандисткой машины.

Помимо этого, весьма интересным (но при этом и большим по объему) является количественный метод исследования ИО и ПсО, а именно:

1) Подсчет отдельных случаем компьютерных атак, информационных «утечек»

2) Смысловой анализ новостных источников (СМИ и Интернет)

3) Отслеживание появления «белых», «серых» и «черных» пропагандистских материалов.

4) Отслеживание официальных заявлений как государственных, так и надгосударственных структур.

5) Отслеживание заявлений от негосударственных акторов - различных группировок, террористических организаций, правозащитных организаций, НКО.

\section{Библиография}

1. Бернейс Э. М.: Пропаганда.- M., Hippo Publishing LTD, 2010

2. Лайнбарджер. П. Психологическая война.- М.: 1962

3. Газетов В. «Когда журналист сильнее солдата»-М., Независимое военное обозрение 04.04.2014

4. Манойло А.В. Модели информационного воздействия на разрешение международных и внутриполитических конфликтов. // Федерализм.-2008.-№3. - С. 159-172.

5. Манойло А.В. Психологические операции США в Ираке. // Космополис.-2008.-№1. - С.124-128.

6. Манойло А.В. Модель информационно-психологической операции в международных конфликтах // Право и политика.-2008.-№6. - С.1387-1394.

7. Манойло А.В. Стратегии “управляемого хаоса" в условиях хаотизации международных отношений: миф или реальность? // NB: Международные отношения. - 2014.-№1.-C.1-3. DOI: 10.7256/23064226.2014.1.10750. URL: http://e-notabene.ru/wi/article_10750.html

8. Манойло А.В. Управление психологической войной // Международные отношения.-2013.-3.-С. 377389. DOI: 10.7256/2305-560Х.2013.3.6221.

9. Петренко А.И. Теоретические основы организации противодействия использованию арсенала сил, средств и методов информационно-психологической войны в политических целях // Тренды и управление.-2014.-2.-C. 154-167. DOI: 10.7256/2307-9118.2014.2.12412.

10. А.В. Манойло Парадигмы управления международным конфликтами: конкуренция или конфронтация // Национальная безопасность / nota bene.-2011.-5.-C. 135-142.

11. Карпович О.Г. Современные концепции и модели управления международными конфликтами (сравнительный политологический анализ) // Национальная безопасность / nota bene.-2013.-4.-C. 605-612. DOI: 10.7256/2073-8560.2013.4.6434. 
12. Карпович О.Г. Проблемы и перспективы исследования современных концепций, моделей и технологий управления международными конфликтами // Национальная безопасность / nota bene.-2013.-5.-C. 80-93. DOI: $10.7256 / 2073-8560.2013 .5 .6432$.

13. Курилкин А.В.Эволюционноеразвитиепсихологическойборьбы: от пропаганды кпсихологическим операциям // Международные отношения.-2014.-3.-C. 472-474. DOI: 10.7256/2305-560X.2014.3.11855.

14. Валиуллин И.И.Эволюция понятия «информационная война» в политической науке // Международные отношения.-2014.-1.-C. 68-74. DOI: 10.7256/2305-560Х.2014.1.10064.

15. Костюхин A.A., Киреев C.A. Сирия: гражданская война или реализация стратегии 4GW? // Международные отношения.-2013.-2.-C. 177-184. DOI: 10.7256/2305-560X.2013.02.10.

16. Курилкин А.В. Современные подходы к ведению информационных войн // Международные отношения.-2014.-1.-C. 75-80. DOI: 10.7256/2305-560X.2014.1.10063.

17. Т.П. Петрова Отношения США - Перу: Монроизм vs Боливаризма // Национальная безопасность / nota bene.-2012.-2.-C. 104-110.

18. Овсянникова О.А., Кузнецова А.А. исторические и современные социально-политические основы российского патриотизма // NB: Международные отношения.-2013.-3.-C. 87-114. DOI: 10.7256/23064226.2013.3.9083. URL: http://www.e-notabene.ru/wi/article_9083.html

19. А.В. Манойло Технологии психологического воздействия на конфликты (на примере революций на Ближнем Востоке и в Северной Африке) // Психология и Психотехника.-2011.-5.-C. 73-80.

20. Акопов Г.Л. Хактивизм в процессе информационно-политических конфликтов // NB: Национальная безопасность.-2014.-1.-C. 24-32. DOI: 10.7256/2306-0417.2014.1.11609. URL: http://www.e-notabene. $\mathrm{ru} / \mathrm{nb} /$ article_11609.html

21. Рувинский Р.3.. 9 тезисов о современной войне и трансформации международного правопорядка. // Право и политика.-2014.-№7.-C. 922-928. DOI: 10.7256/1811-9018.2014.7.11929

22. Владимирова Т.В.. Информационная безопасность: социальные практики и структуры. // Национальная безопасность / nota bene.-2014.-№3.-C. 390-397. DOI: 10.7256/2073-8560.2014.3.11511

23. Владимирова Т.В.. Уровень интенсивности коммуникации как критерий обеспечения информационной безопасности. // Политика и Общество.-2014.-№4.-C. 461-469. DOI: 10.7256/1812-8696.2014.4.10883

24. Сурма И.В., Анненков В.И., Карпов В.В., Моисеев А.В.. «Сетецентрическое управление»: современная парадигма развития систем управления в вооруженных силах ведущих держав мира. // Национальная безопасность / nota bene.-2014.-№2.-C. 317-327. DOI: 10.7256/2073-8560.2014.2.1139

\section{References}

1. Berneis E. M.: Propaganda. - M., Hippo Publishing LTD, 2010

2. Lainbardzher. P. Psikhologicheskaya voina. - M.: 1962

3. Gazetov V. «Kogda zhurnalist sil'nee soldata»-M., Nezavisimoe voennoe obozrenie 04.04.2014

4. Manoilo A.V. Modeli informatsionnogo vozdeistviya na razreshenie mezhdunarodnykh i vnutripoliticheskikh konfliktov. // Federalizm.-2008.-№3. - S. 159-172.

5. Manoilo A.V. Psikhologicheskie operatsii SShA v Irake. // Kosmopolis.-2008.-№1. - S.124-128.

6. Manoilo A.V. Model' informatsionno-psikhologicheskoi operatsii v mezhdunarodnykh konfliktakh // Pravo i politika.-2008.-№6. - S.1387-1394.

7. Manoilo A.V. Strategii "upravlyaemogo khaosa" v usloviyakh khaotizatsii mezhdunarodnykh otnoshenii: mif ili real'nost'? // NB: Mezhdunarodnye otnosheniya. — 2014.-№1.-S.1-3. DOI: 10.7256/2306-4226.2014.1.10750. URL: http://e-notabene.ru/wi/article_10750.html

8. Manoilo A.V. Upravlenie psikhologicheskoi voinoi // Mezhdunarodnye otnosheniya.-2013.-3.-C. 377-389. DOI: 10.7256/2305-560X.2013.3.6221.

9. Petrenko A.I. Teoreticheskie osnovy organizatsii protivodeistviya ispol'zovaniyu arsenala sil, sredstv i metodov informatsionno-psikhologicheskoi voiny v politicheskikh tselyakh // Trendy i upravlenie.-2014.2.-C. 154-167. DOI: 10.7256/2307-9118.2014.2.12412. 


\section{Тренды и управление 3(7) • 2014}

10. A.V. Manoilo Paradigmy upravleniya mezhdunarodnym konfliktami: konkurentsiya ili konfrontatsiya // Natsional'naya bezopasnost' / nota bene.-2011.-5.-C. 135-142.

11. Karpovich O.G. Sovremennye kontseptsii i modeli upravleniya mezhdunarodnymi konfliktami (sravnitel'nyi politologicheskii analiz) // Natsional'naya bezopasnost' / nota bene.-2013.-4.-C. 605-612. DOI: 10.7256/2073-8560.2013.4.6434.

12. Karpovich O.G. Problemy i perspektivy issledovaniya sovremennykh kontseptsii, modelei i tekhnologii upravleniya mezhdunarodnymi konfliktami // Natsional'naya bezopasnost' / nota bene.-2013.-5.-C. 80-93. DOI: $10.7256 / 2073-8560.2013 .5 .6432$.

13. Kurilkin A.V.Evolyutsionnoe razvitie psikhologicheskoi bor'by: ot propagandy kpsikhologicheskim operatsiyam // Mezhdunarodnye otnosheniya.-2014.-3.-C. 472-474. DOI: 10.7256/2305-560X.2014.3.11855.

14. Valiullin I.I. Evolyutsiya ponyatiya «informatsionnaya voina»v politicheskoi nauke // Mezhdunarodnye otnosheniya.-2014.-1.-C. 68-74. DOI: 10.7256/2305-560X.2014.1.10064.

15. Kostyukhin A.A., Kireev S.A. Siriya: grazhdanskaya voina ili realizatsiya strategii 4GW? // Mezhdunarodnye otnosheniya.-2013.-2.-C. 177-184. DOI: 10.7256/2305-560X.2013.02.10.

16. Kurilkin A.V. Sovremennye podkhody k vedeniyu informatsionnykh voin // Mezhdunarodnye otnosheniya.2014.-1.-C. 75-80. DOI: 10.7256/2305-560X.2014.1.10063.

17. T.P. Petrova Otnosheniya SShA - Peru: Monroizm vs Bolivarizma // Natsional'naya bezopasnost' / nota bene.-2012.-2.-C. 104-110.

18. Ovsyannikova O.A., Kuznetsova A.A. istoricheskie i sovremennye sotsial'no-politicheskie osnovy rossiiskogo patriotizma // NB: Mezhdunarodnye otnosheniya.-2013.-3.-C. 87-114. DOI: 10.7256/2306-4226.2013.3.9083. URL: http://www.e-notabene.ru/wi/article_9083.html

19. A.V. Manoilo Tekhnologii psikhologicheskogo vozdeistviya na konflikty (na primere revolyutsii na Blizhnem Vostoke i v Severnoi Afrike) // Psikhologiya i Psikhotekhnika.-2011.-5.-C. 73-80.

20. Akopov G.L. Khaktivizm v protsesse informatsionno-politicheskikh konfliktov // NB: Natsional'naya bezopasnost'.-2014.-1.-C. 24-32. DOI: 10.7256/2306-0417.2014.1.11609. URL: http://www.e-notabene. $\mathrm{ru} / \mathrm{nb} /$ article_11609.html

21. Ruvinskii R.Z.. 9 tezisov o sovremennoi voine i transformatsii mezhdunarodnogo pravoporyadka. // Pravo i politika.-2014.-№7.-C. 922-928. DOI: 10.7256/1811-9018.2014.7.11929

22. Vladimirova T.V.. Informatsionnaya bezopasnost': sotsial'nye praktiki i struktury. // Natsional'naya bezopasnost' / nota bene.-2014.-№3.-C. 390-397. DOI: 10.7256/2073-8560.2014.3.11511

23. Vladimirova T.V.. Uroven' intensivnosti kommunikatsii kak kriterii obespecheniya informatsionnoi bezopasnosti. // Politika i Obshchestvo.-2014.-№4.-C. 461-469. DOI: 10.7256/1812-8696.2014.4.10883

24. Surma I.V., Annenkov V.I., Karpov V.V., Moiseev A.V.. «Setetsentricheskoe upravlenie»: sovremennaya paradigma razvitiya sistem upravleniya v vooruzhennykh silakh vedushchikh derzhav mira. // Natsional'naya bezopasnost' / nota bene.-2014.-№2.-C. 317-327. DOI: 10.7256/2073-8560.2014.2.1139 